\title{
Do jornal para o livro: ensaios curtos de cientistas
}

\author{
Luiz Fernando Dal Pian Nobre*
}

\begin{abstract}
Resumo
Análise das narrativas de três coletâneas de ensaios curtos sobre Ciência \& Tecnologia, editadas a partir da publicação periódica de textos em colunas de jornais - impresso e digital, de grande circulação, escritos por cientistas interessados em aproximar o cidadão leigo, não especialista, da discussão técnica. Objetiva-se identificar as categorias temáticas predominantes nos textos e elucidar a presença de particularidades discursivas capazes de indicar a emergência de um "gênero" de "ensaios curtos" no espaço da divulgação científica. A metodologia inclui análise categorial do conteúdo dos 294 ensaios sobre 8 (oito) categorias temáticas principais e 93 registros de subcategorias temáticas mais recorrentes. A análise da abordagem discursiva presente nos ensaios revelou uma tendência ao uso de recursos artístico-literários associados a uma estrutura que espelha a organização dos artigos publicados em periódicos científicos, fonte de inspiração dos ensaios. Palavras chave: Livro. Ensaios curtos. Acontecimento científico. Análise temática. Relação ciência-sociedade.
\end{abstract}

\section{From the newspaper for the book: short essays of scientists Abstract}

This work is an analysis' narratives of three texts of short essay's books about Science \& Technology, edited from a selection of short texts regularly published in columns of highly circulated newspapers - print and digital, written by scientists interested in bringing ordinary people closer to technical discussion. Our goal is to identify the thematic categories prevalent in the texts and to elucidate

\footnotetext{
* Doutorando pelo Programa de Pós-Graduação em Ciências da Comunicação (PPGCOM) da ECA-USP, São Paulo-SP, Brasil. Mestre pelo Programa Regional de Pós-Graduação em Desenvolvimento e Meio Ambiente (PRODEMA) da Universidade Federal do Rio Grande do Norte (UFRN). E-mail: lfdalpian@usp.br
} 
the presence of discursive particularities that could indicate the emergence of a "genre" of "short essays" on the field of science communication. About methodology, we use the categorical content analysis from 294 essays about 8 (eight) identified eight main thematic categories and 93 subcategories. The analysis revealed a trend toward the use of artistic and literary resources associated with a structure that mirrors the organization of articles published in scientific journals - inspiration sources for the essays.

Keywords: Book. Short essays. Scientific occurrence. Thematic analysis. Science-society relationship.

\section{Del periódico para el libro: ensayos cortos de científicos Resumen}

Este trabajo es un análisis de las narrativas de tres libros de colecciones de ensayos cortos sobre Ciencia y Tecnología editadas a partir de la publicación periódica de textos cortos en las columnas de periódicos - impresión y distribución digital, de gran circulación, escritos por científicos interesados en aproximar lo ciudadano lego, no experto, de la discusión técnica. El objetivo es identificar los temas predominantes en los textos y dilucidar la presencia de particularidades discursivas que pueden indicar la emergencia de un "género" en "ensayos cortos" en el espacio de la divulgación científica. La metodología incluye el análisis categorial de los contenidos de los 294 ensayos en 8 (ocho) categorías temáticas principales y 93 registros de subcategorías temáticas más recurrentes. El análisis del enfoque discursivo revela una tendencia para el uso de recursos artísticos y literarios relacionados a una estructura que refleja la organización de los artículos publicados en revistas científicas, que es fuente de inspiración de los ensayos. Palabras clave: Libro. Ensayos cortos. Acontecimiento científico. Análisis temática. Relación ciencia-sociedad.

\section{Introdução}

busca pelo fortalecimento do debate público sobre Ciên-
cia, Tecnologia e Inovação (CT\&I) no Brasil não é algo
recente e tem ainda pela frente muitos desafios. Um deles 
Esse receio acentuou-se com o crescimento da divulgação científica na imprensa diária que, adepta do imediatismo e da concisão, e visando alcançar um número maior de leitores, procura simplificar a complexidade da linguagem científica. A finalidade dessa simplificação é tornar o conhecimento científico mais acessível ao leitor não-especialista. Mas, para muitos pesquisadores, ela pode provocar distorções inadmissíveis (GOMES, 2002, p.4).

Os jornalistas, por outro lado, costumam argumentar que muitas dessas deturpações apontadas pelos cientistas nas matérias não deveriam ser consideradas como equívocos, e sim como resultado da adaptação do discurso científico ao discurso jornalístico.

Diante de tal problemática, pesquisadores têm sido estimulados a abandonar o confinamento de seus laboratórios para se comunicar diretamente com a sociedade. O movimento de abertura vem ganhando adesão crescente na atual era digital caracterizada pela Sociedade em Rede (CASTELLS, 1999, p.38-39) e ampliando as possibilidades de interação pesquisador-público e de aproximação ciência-sociedade por meio das novas Tecnologias da Informação e Comunicação (TICs).

Nem sempre o jornalista participa como mediador. Plataformas e gêneros jornalísticos tradicionais, como o jornal e a coluna, vêm sendo recorrentemente utilizados por alguns cientistas que vislumbram a possibilidade de praticar suas técnicas de escrita para popularizar fatos cotidianos relacionados ao universo científico e tecnológico. Podemos citar como exemplos de sucesso o físico Marcelo Gleiser e a neurocientista Suzana Herculano-Houzel, colunistas do jornal Folha de S.Paulo; e o biólogo Fernando Reinach, colunista do jornal Estado de S.Paulo. Todos escrevem com uma periodicidade específica e lançaram pelo menos um livro com uma seleção de textos publicados em suas colunas ou em seus websites. Tais livros apresentam-se como uma coletânea de "ensaios curtos" acerca de fatos científicos e visam aproximar o cidadão leigo, não especialista, da discussão técnica.

O presente trabalho analisa o conteúdo das narrativas de três livros - um de cada autor citado. Mais especificamente pretendeu-se: identificar as categorias temáticas predominantes nos textos; avaliar o tipo de abordagem discursiva dada aos temas; e elucidar 
a presença ou não de particularidades discursivas capazes de indicar a emergência de um "gênero" de "ensaios curtos" no espaço da divulgação científica. Compreender o processo de construção narrativa sobre CT\&I, de transcrição e adaptação de produções científicas para textos curtos em jornais (impresso e digital), torna-se relevante àqueles que têm interesse em buscar novas formas de se comunicar e de se aproximar do público leigo, numa era caracterizada pelos avanços das TICs, disseminação do acesso à Internet, fluxo livre de informações e convergência midiática.

\section{Quadro teórico de referência}

\section{Relação ciência e imprensa: novas perspectivas}

Há muito tempo a sociedade demonstra interesse por assuntos relacionados à ciência e tecnologia. Na verdade, desde a pré-história, o homem busca explicações para a realidade e os mistérios do mundo que o cerca. Observou os movimentos das estrelas, manuseou o fogo, aprendeu a usar ferramentas em seu favor, buscou respostas para os fenômenos da natureza. Independentemente dos mitos, lendas e crenças que moldaram as culturas mais primitivas, o pensamento humano sempre esteve, de alguma forma, atrelado ao conhecimento científico, que se renovou e se disseminou com o passar dos séculos.

Ao longo do percurso a sociedade testemunhou diversas revoluções científicas, no sentido de Kuhn (1970, p.25), e está, cada vez mais, familiarizando-se com o universo das pesquisas e dos pesquisadores. No Brasil, a produção científica cresceu três vezes mais do que a média mundial nas últimas três décadas (REZENDE, 2011, p.205). Em 2008, o país alcançou a 13a colocação no ranking internacional de produção/publicações, ultrapassando países com certa tradição científica como Rússia e Holanda.

No entanto, mesmo com todo o aparato tecnológico que tem possibilitado o acesso praticamente instantâneo à informação, questiona-se tanto aspectos quantitativos como qualitativos dos conteúdos sobre ciência veiculados pelos Meios de Comunicação de Massa. Segundo Bueno (2010, p.3), a divulgação, por meio 
do Jornalismo Científico, está longe do ideal. Na grande mídia, a ciência e a tecnologia ficam relegadas a segundo plano, restritas a notas e notícias isoladas, numa cobertura que busca sempre valorizar o espetáculo e o sensacionalismo. As exceções ficam por conta dos veículos especializados no assunto, como revistas, cadernos específicos em jornais, sites e demais mídias alternativas. A televisão aberta, principal veículo condutor de conteúdos culturais, em um país ainda marcado pelos reduzidos níveis de escolaridade, não contribui como deveria para o processo de "alfabetização científica", exibindo programas sobre o tema em horários de baixa audiência.

De acordo com Medina (2006, p.23), a prática de traduzir a linguagem cifrada da ciência para uma linguagem acessível ao público, comum nos veículos de Comunicação que cobrem o tema, evidencia uma visão extremamente funcional e empobrecida das mediações sociais, que submete o jornalista a uma competência exclusivamente técnica, quase gramatical, no sentido de um texto legível. A autora defende que é preciso ampliar os diálogos, estimular o saber plural e complexo, confrontar sabedorias cotidianas, artísticas, filosóficas, religiosas, ideológicas e do senso comum, fugindo das narrativas fragmentadas e reducionistas.

Mas até que ponto é relevante incluir a sociedade de massa na esfera de discussão de um grupo seleto de estudiosos? Segundo Albagli (1996, p.397), a promoção da informação científica contribui para o processo de construção da cidadania, quando possibilita a ampliação do conhecimento e da compreensão do público leigo a respeito do processo científico e de sua lógica; no momento em que constrói uma opinião pública informada sobre os impactos do desenvolvimento científico e tecnológico sobre a sociedade; e quando permite a ampliação da possibilidade e da qualidade de participação da sociedade na formulação de políticas públicas e na escolha de opções tecnológicas, especialmente em um país onde a grande maioria dos investimentos na área são públicos.

Diante do espaço ainda inexpressivo para as coberturas sobre CT\&I nos Meios de Comunicação de Massa, segundo Schmidt $(2009$, p.550), os pesquisadores estão sendo encorajados a 
estimular a alfabetização científica, fazendo uso de uma linguagem clara e acessível ao público. E de fato, alguns deles têm se apresentado como legítimos porta-vozes de importantes áreas do conhecimento como as neurociências, a física, a astronomia e as ciências ambientais. No exterior, alguns livros chegam a atingir o status de best-sellers - mais vendidos de um período em um local (REIMÃO, 1996, p.23), como é o caso de obras do físico Stephen Hawking, do biólogo Richard Dawkins, do astrônomo Carl Sagan e do neurologista Oliver Sacks. O mercado brasileiro de livros de divulgação científica ganhou um fôlego inédito na última década, mas só agora está "saindo da infância” (MARQUES, 2010). Ainda não é comum encontrar sessões específicas deste gênero nas nossas livrarias e tampouco nas listas nacionais de best-sellers.

\section{Ensaios curtos: do jornal para o livro}

Visando aproximar-se da sociedade, os cientistas têm feito uso crescente de Meios de Comunicação como sites especializados, blogs, colunas e, mais recentemente, redes sociais. Na plataforma impressa, a coluna em jornais e o livro têm servido como importantes espaços de difusão científica, inclusive, complementares.

A coluna representa uma seção em um jornal na qual um redator, jornalista ou não, tem liberdade para construir textos opinativos sobre temas variados. Segundo Melo (2003, p.139), a caracterização do colunismo na imprensa brasileira dá margem a ambiguidades. Há uma tendência para chamar de coluna toda seção fixa no jornal, o que abrangeria, segundo esse conceito, artigos, comentários, contos, crônicas e até mesmo resenhas. Em tal perspectiva, a coluna seria definida como:

Seção especializada de jornal ou revista, publicada com regularidade, geralmente assinada, e redigida em estilo mais livre e pessoal do que o noticiário comum. Compõe-se de notas, suetos, crônicas, artigos ou textos-legendas, podendo adotar, lado a lado, várias dessas formas. As colunas mantêm um título ou cabeçalho constante e são diagramadas geralmente numa posição fixa e sempre na mesma página, o que facilita a sua localização imediata pelos leitores (MELO, 2003. p.139-140). 
Desde meados dos anos 1950 até os dias de hoje, as teorias classificatórias de gêneros jornalísticos têm sido objeto de debate constante e de divergências. Independentemente da classificação do gênero, essas publicações periódicas assinadas por cientistas interessados em popularizar ciência, apesar do espaço relativamente reduzido, representam uma alternativa oportuna de aproximação na relação ciência-sociedade.

É interessante observar que o esforço dos pesquisadores-colunistas em ocupar um espaço jornalístico vem sendo acompanhado pela conquista do espaço editorial de livros, em que ensaios curtos são selecionados no sentido de compor uma obra literária. É o caso dos livros analisados nesse estudo: O cérebro nosso de cada dia - Descobertas da neurociência sobre a vida cotidiana, de Herculano-Houzel (2002); Micro Macro 2 - Mais reflexões sobre o Homem, o Tempo e o Espaço, de Gleiser (2007); e A longa marcha dos grilos canibais - E outras crônicas sobre a vida no planeta Terra, de Reinach (2010).

Enquanto o livro de Herculano-Houzel, o mais antigo, não apresenta classificação literária, o livro de Gleiser é catalogado como "Artigos" e o livro de Reinach, o mais recente, como "Crônicas". Traduzidos para a língua inglesa, estes livros seriam eventualmente catalogados como "short stories" ("estórias curtas"), gênero que abarca tanto as crônicas, quanto os contos brasileiros.

A seleção de crônicas, contos, colunas ou ensaios curtos (seja qual for a classificação) para publicação posterior em forma de livro não é uma novidade. Autores renomados da nossa Literatura como Machado de Assis, Lima Barreto, Carlos Drummond de Andrade, Fernando Sabino, Clarice Lispector, Moacyr Scliar, Luis Fernando Veríssimo, dentre outros, foram e continuam tendo suas crônicas e contos reeditados em livro. Não é recente também a abordagem de temas de interesse da ciência por parte desta literatura de "estórias curtas". Acaba sendo natural para os escritores de "estórias curtas" - produtores simbólicos, reconstrutores dos acontecimentos de seu tempo - abordar temas que nos inquietam enquanto seres humanos, como a origem do universo e da vida, os avanços tecnológicos e suas consequências, as questões ambientais, os problemas de saúde, dentre outros. 
Mas no tocante à publicação sistemática de textos curtos, concisos e sintéticos sobre temas científicos, podemos afirmar que estamos entrando em uma esfera nova e inovadora, com a possibilidade de alcançar resultados muito frutíferos.

De acordo com Barbosa (2003, p.221), o acontecimento descrito pelos redatores de jornal não representa a realidade em si, mas sim uma reconstrução da realidade, do ponto de vista do narrador, que é submetido aos limites ideológicos do seu tempo e às estruturas às quais está filiado. A autora cita a pesquisa do semiólogo argentino Eliséo Veron, intitulada Construir o Acontecimento, destacando que as mídias não descrevem, mas constroem a realidade. Assim, o mundo configurado pelas empresas jornalísticas é sempre uma realidade construída.

Considera-se, pois, o acontecimento não como ocorrência espacial e temporal, mas como algo que, ao ser editado, selecionado, escolhido, recebe sentidos atribuídos pelos chamados operadores da mídia. Nessa perspectiva, portanto, os acontecimentos públicos seriam produto ou resultado das atividades, das práticas rotineiras e das estratégias de um certo número de atores sociais (BARBOSA, 2003, p. 221).

Apesar de, tecnicamente, Jornalismo e Literatura estarem em situações distintas em termos de classificação, processos e produtos, ambos sempre traçaram - e continuam traçando - caminhos paralelos, integrando-se e complementando-se. E na complexa arte de escrever sobre CT\&I, de construir acontecimentos científicos para consumo do público geral, as perspectivas de sucesso podem ser semelhantes.

\section{Procedimentos metodológicos}

Para executar nosso estudo foi escolhida como metodologia a Análise de Conteúdo (AC), umas das técnicas mais utilizadas para o tratamento de dados brutos de Comunicações nas Ciências Sociais empíricas, com o caráter de pesquisa híbrida, abordando tanto aspectos quantitativos como qualitativos (BARDIN, 2004, p.42). No nosso caso específico, analisamos o conteúdo dos acon- 
tecimentos científicos construídos na forma de ensaios curtos em colunas de jornal impresso e digital, selecionados e organizados em três livros por cientistas redatores.

\section{Etapas do Estudo}

Bardin (2004) organiza a análise de conteúdo em três fases principais: pré-análise, exploração do material e tratamento dos resultados (a inferência e a interpretação). A pré-analise é a fase de organização do material, da escolha dos documentos que serão submetidos à análise, da formulação dos objetivos que irão nortear a pesquisa e dos indicadores que irão fundamentar a interpretação final. Selecionamos três livros de autores cientistas diferentes que, no nosso entender, desempenham um importante papel de divulgação científica, por meio de suas colunas em dois dos jornais mais vendidos do país, Folha de S.Paulo e O Estado de S.Paulo. Os livros analisados e seus respectivos autores são:

\section{O cérebro nosso de cada dia - Descobertas da neurociência sobre a vida cotidiana, de Suzana Herculano-Houzel}

O livro, publicado em 2002, é o primeiro de sete escritos pela neurocientista. Tal como os outros dois livros aqui analisados, apresenta-se como uma coletânea de ensaios curtos. No entanto, diferentemente dos outros dois, este não é resultado de textos selecionados de sua coluna no jornal impresso. Na verdade, são originais de uma revista eletrônica disponibilizada na internet sob o título $O$ cérebro nosso de cada dia ${ }^{1}$, publicados entre 2000 e 2002. O livro reúne 47 ensaios curtos baseados, segundo a autora, "em artigos científicos publicados em periódicos de renome como Nature, Science e The Journal of Neuroscience" (HERCULANO. -HOUZEL, 2002, p.18).

Suzana Herculano-Houzel nasceu no Rio de Janeiro, em 1972. Formada em biologia pela Universidade Federal do Rio de Janeiro, obteve o doutorado em Neurociências pela Université Paris

\footnotetext{
1 www.cerebronosso.bio.br
} 
VI. Sua coluna é publicada quinzenalmente, às terças feiras, no caderno Equilíbrio da Folha de S.Paulo, na qual aborda atualidades e curiosidades das pesquisas na área das neurociências. A coluna fica disponível para acesso no portal de notícias da Folha. Escreveu livros de divulgação científica, sendo que um deles, Por que o bocejo é contagioso?, que resultou em um quadro de 24 episódios no programa Fantástico da Rede Globo, chamado Neurológica, que explicou diversas curiosidades do funcionamento cerebral.

\section{Micro Macro 2 - Mais reflexões sobre o Homem, o Tempo e o Espaço, de Marcelo Gleiser}

Publicado em 2007, o livro segue o mesmo modelo da primeira versão lançada (Micro Macro) em 2005, reunindo colunas selecionadas na Folha de S.Paulo, veiculadas de 1999 a 2004. Este, o segundo, Micro Macro 2, traz todos os textos publicados em sua coluna, de 2004 a 2007, totalizando 136 artigos (gênero definido na catalogação bibliográfica), sobre assuntos bastante variados, que vão da física, passando pela cosmologia, religião, filosofia e história da ciência. Em alguns textos, há referência a pesquisas publicadas em periódicos científicos como a Science.

Marcelo Gleiser nasceu no Rio de Janeiro, em 1959. Formado em física pela Pontifícia Universidade Católica do Rio de Janeiro, obteve o doutorado no King's College, na Inglaterra, em 1986. Escreve na coluna Micro Macro, da Folha de S.Paulo, semanalmente, aos domingos, quando são discutidos temas científicos diversos, com foco na física e na astronomia. Sua coluna está disponível para acesso no portal de notícias da Folha. Em 2001, ganhou o prêmio José Reis de Divulgação Científica. Publicou livros sobre divulgação e, em 2006, apresentou uma série de 12 episódios no programa Fantástico da Rede Globo, chamado Poeira das Estrelas, que abordou temas relacionados à física e à origem do universo.

\section{A longa marcha dos grilos canibais - E outras crônicas sobre a vida no planeta Terra, de Fernando Reinach}

Livro publicado em 2010, reúne uma seleção de colunas veiculadas no jornal O Estado de S.Paulo, entre 2004 e 2009, sob 
critérios arbitrários e de interesses pessoais do autor (REINACH, 2010, p.14). A obra está estruturada em 111 crônicas (gênero definido no subtítulo da obra e na catalogação bibliográfica) sobre temas diversos, com ênfase para as ciências ambientais. Ao final de cada texto, na maior parte das vezes, Fernando Reinach faz referência a algum periódico científico, fonte dos conceitos discutidos, com predominância para as revistas Science e Nature.

Fernando Reinach nasceu em São Paulo, em 1956. Formado em Biologia pela Universidade de São Paulo em 1978, obteve o doutorado na Cornell University, nos Estados Unidos, em 1984, e o pós-doutorado em Cambridge, na Inglaterra, em 1986. Sua coluna é publicada no caderno Vida do jornal O Estado de S.Paulo, às quintas-feiras, quando aborda temas científicos diversos, com maior ênfase na divulgação de pesquisas nas ciências ambientais. A coluna fica disponível para acesso no portal de notícias do Estadão. Mantém uma relação próxima com a imprensa, de modo que é frequentemente citado como fonte em reportagens científicas.

\section{Análise temática}

Dentre as técnicas mais utilizadas nas análises de conteúdos jornalísticos está a Análise Categorial ou Temática, que foi aplicada nesta pesquisa. Essa técnica consiste no desmembramento do texto em unidades (categorias), visando descobrir os núcleos de sentido que compõem uma Comunicação. Preocupa-se com a frequência desses núcleos, sob forma de dados segmentáveis e comparáveis e não com sua dinâmica e organização (SILVA, 2005, p.65). Para a análise temática, determinamos oito grupos de categorias e suas respectivas subcategorias, de acordo com seus enquadramentos, seus núcleos de sentido. Muitos textos receberam mais de um tipo de enquadramento, sendo todos computados em suas respectivas categorias. Diante da diversidade de temáticas abordadas nos ensaios, pontuamos aqueles que consideramos mais relevantes e recorrentes. Em alguns casos, subcategorias se repetiram em certos grupos temáticos. As categorias e subcategorias foram: 
- Ambiente: Biologia; Ecologia; Geologia; Biodiversidade; Ecossistemas; Mudanças Climáticas; Sustentabilidade; Água; Extinção; Impactos Ambientais; Evolução; Genética; Demografia; Regeneração; Agricultura; Políticas; Terremotos; Vulcões; e Elementos Químicos.

- Universo: Física; Astronomia; Cosmologia; Partículas; Ficção Científica; Expansão; Buracos Negros; Gravidade; Marés; Vida Extraterrestre; Luz; Cometas; Eletricidade; Sistema Solar; Big Bang; e Matemática.

- História: História da Ciência; Genética; Evolução; Arqueologia; Paleontologia; Origem da Vida; Biografia; Demografia; Extinção; Guerras; Elementos Químicos; Agricultura; Nutrição; Arte; Escrita; e Pintura.

- Cérebro: Neurociências; Mente; Sentidos; Memória; Consciência; Raciocínio; Genética; Aprendizado; Personalidade; Estrutura Cerebral; Percepção; Emoções; Inteligência; Evolução; Mito; Células Cerebrais; Sinapses; Oxigenação; Efeito Placebo; Movimento; Sono; Sonho; Hormônios; Bocejo; Vícios; Localização; Exercício Cerebral; e Parapsicologia.

- Saúde: Doenças; Tratamentos; Genética; Nutrição; Energia; Políticas; Medicamentos; Drogas; Vícios; Substâncias Tóxicas; Maternidade; e Células-Tronco.

- Comportamento: Reprodução; Acasalamento; Genética; Sexualidade; Evolução; Adaptação; Mecanismos de Defesa; Parasitismo; Solidariedade; Migração; Canibalismo; Alimentação; Localização; Locomoção; Autofagia; Maternidade; Sexualidade; Culturas.

- Tecnologia: Biotecnologia; Nanotecnologia; Genética; Robótica; Informática; e Tratamentos.

- Filosofia da Ciência: Metafísica; Revoluções Científicas; Ética; Moral; Metodologias Científicas; Religião; Interdisciplinaridade; Evolucionismo vs. Criacionismo; Obscurantismo; e Políticas.

Ao todo, foram analisados 294 ensaios curtos. É importante destacar que não foi objetivo da pesquisa realizar uma análise 
comparativa entre os colunistas, e sim a análise dos ensaios como um todo.

Após a pré-analise, trabalhamos a fase de exploração do material, com a leitura, codificação, enumeração dos temas em função das regras previamente formuladas. Os dados receberam tratamento quantitativo (cálculos percentuais) e qualitativo (análise da natureza da abordagem discursiva presente nos "ensaios curtos” no espaço da Comunicação Científica). À luz dos objetivos almejados, foram realizadas inferências e interpretações que levaram à discussão final dos resultados.

\section{Resultados e discussões}

Dos 294 ensaios curtos analisados, chegamos ao número de 93 categorias temáticas, nas quais obtivemos a frequência total de 419 registros, divididos em oito eixos principais (Tabela 01). Cada autor tratou de temas científicos diversos, mas sempre com uma maior recorrência para aqueles ligados as suas respectivas áreas de formação e atuação, como a astrofísica, as ciências biológicas e as neurociências. Estas áreas do conhecimento estão recebendo, de fato, um destaque expressivo nos Meios de Comunicação que se propõem a popularizar ciência, uma vez que o fascínio pelos mistérios do universo, pelas questões ambientais e pelas novas descobertas sobre o funcionamento do nosso cérebro continuam em alta nas pautas jornalísticas.

Tabela 1 - Categorias temáticas dos textos publicados

\begin{tabular}{ccc}
\hline Categorias & Frequência & Porcentagem \\
\hline Universo & 86 & $20.5 \%$ \\
\hline Ambiente & 76 & $18.1 \%$ \\
\hline Cérebro & 68 & $16.2 \%$ \\
\hline História & 62 & $14.8 \%$ \\
\hline Saúde & 46 & $11 \%$ \\
\hline Comportamento & 39 & $9.3 \%$ \\
\hline Filosofia da Ciência & 33 & $7.9 \%$ \\
\hline Tecnologia & 9 & $2.1 \%$ \\
\hline Total & 419 & $100 \%$ \\
\hline
\end{tabular}


Dentre os critérios de noticiabildade - os valores-notícia (WOLF, 2003, p.202), utilizados para a escolha dos assuntos -, identificamos a recorrência de temas que atiçam a curiosidade humana, como é o caso da origem da vida, das novas descobertas que rompem paradigmas, das revelações inusitadas sobre os nossos antepassados, dos tratamentos avançados da medicina, das perspectivas futuras para um mundo marcado pelas inovações tecnológicas, dentre outros fatos (comprovados cientificamente ou não) que repercutem socialmente.

Uma das constatações mais interessantes diz respeito ao esforço dos cientistas redatores em fazer uso de certas ferramentas narrativas, visando cumprir a difícil missão de aproximar a informação técnica, dominada por um grupo seleto de estudiosos, do público leigo. Cada um, a sua maneira, exercitou (e continua a exercitar) técnicas de escrita, de modo a agregar elementos literários ao texto científico, utilizando um grau de sutileza poética, metáforas, humor, sem a perda da clareza e da essência das informações.

Como exemplo, podemos citar Reinach (2010, p.305) quando simula uma situação em que o milho escreve uma carta para o autor, agradecendo aos humanos o fato de terem desenvolvido técnicas de monocultura para expansão daquela espécie vegetal pelo mundo, de modo a dizimar espécies concorrentes e predadores nos ambientes em que são cultivadas. Ou mesmo quando Herculano-Houzel (2002, p.99), ao explicar cientificamente os bocejos, aposta com o leitor do texto, que o mesmo não conseguirá chegar ao fim da leitura sem bocejar, tamanho são os detalhes descritivos sobre a discussão. Realmente, somos tomados pelo desejo de encher os pulmões de oxigênio.

Já Gleiser (2007), demonstra que o olhar científico sobre a natureza não ofusca sua beleza, como criticam alguns artistas. Por exemplo, ao explicar um arco-íris como sendo a difração da luz solar por gotas d'água em suspensão na atmosfera, o autor escreve:

Imagine essas gotas geladas, pequenos prismas cristalinos flutuando pelo céu, incontáveis diamantes recebendo a luz do Sol, separando-a em suas frequências visíveis, trabalhando juntos para criar um fenômeno de incrível beleza. Será que o arco-íris ficou mais feio? Eu diria que ficou mais bonito. 
Ao entendê-lo nos aproximamos dele. Sua beleza nos inspira a entender ainda mais. E, quanto mais entendemos, mais bonitas as coisas ficam. Essa é a poesia da ciência (GLEISER, 2007, p. 120).

Apesar dos escritores se esforçarem para construir um discurso ao estilo literário, foi possível verificar que a narrativa de uma parte significativa desses ensaios curtos utiliza, na sua organização, uma estrutura semelhante à dos artigos publicados em periódicos científicos, de onde muitas vezes são retiradas as ideias para elaboração dos textos. Inicialmente, é introduzida uma questão a ser discutida, uma problemática e uma hipótese. Em seguida, são apresentados conceitos relacionados ao tema e alguns aspectos metodológicos. Por fim, uma ideia conclusiva e reflexiva é apresentada ao leitor na figura abaixo:

Figura 1 - Modelo de construção narrativa dos ensaios curtos científicos

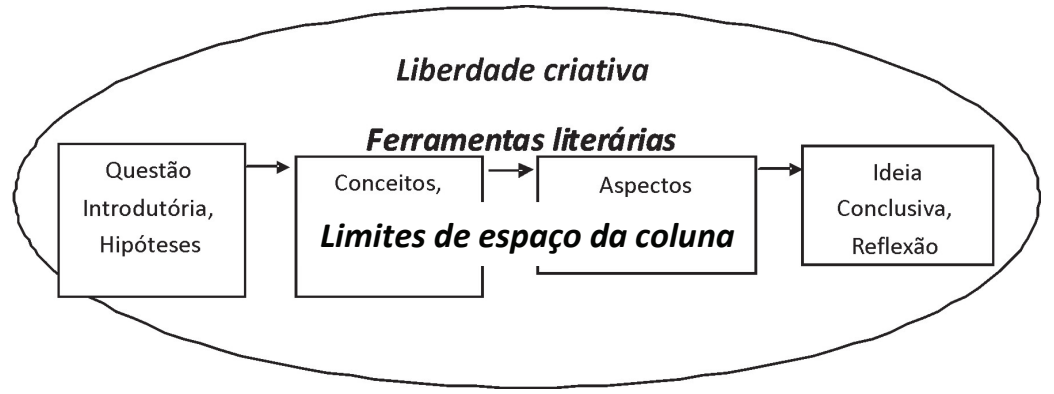

Em outras palavras, essas "estórias curtas" são textos que reconstroem realizações científicas do ponto de vista dos pesquisadores escritores, mesclando recursos literários a uma "topologia" típica dos artigos científicos. No caso de Reinach (2010, p.14), esse esforço chega a ser reconhecido na introdução de seu livro:

O formato de cada texto tenta mimetizar o formato dos trabalhos científicos Primeiro descreve o local de onde a expedição partiu e o que imaginamos que sabemos sobre o assunto. À expedição propriamente dita, experimento a experimento, segue-se a descrição do que foi observado. Por fim, o texto fecha com um parágrafo no qual me permito dar vazão à imaginação e especular sobre o que descobrimos durante a aventura. Meu compromisso de fidelidade com o trabalho original, citado após cada texto, se restringe aos experimentos e resultados. Os delírios da imaginação são de minha responsabilidade. 
Constatamos assim que, por um lado, os cientistas veem-se mais livres das formalidades impostas ao discurso acadêmico que adota estilo próprio (como o uso de citações, paráfrases etc.); por outro lado, enquanto "escritores literários", precisam impressionar os leitores e conquistar sua confiança, sendo levados a recorrer a estratégias discursivo-linguísticas de convencimento e legitimidade.

Uma observação mais cuidadosa dos textos à luz de tal constatação nos remete a uma questão importante: até que ponto a atividade de recontar as "estórias" em estilo literário, preservando a "topologia" dos artigos científicos, não estaria sendo acompanhada de crenças, valores e posições éticas dos próprios pesquisadores escritores acerca do fazer científico? A seguinte colocação de Gleiser (2007, p.39), que questiona a ascensão do obscurantismo religioso, parece apontar nesta direção:

A imposição de valores religiosos vira uma agenda política, comprometendo a separação entre Estado e Igreja e a liberdade de escolha do cidadão [...] É preciso, urgentemente, combater o obscurantismo crescente em nossa sociedade com a única luz que pode brilhar universalmente em todas as casas, a luz da ciência e da razão.

Desta maneira, surgem indícios de que o enaltecimento do saber científico em contraposição às outras formas de conhecimento, como o popular, o religioso, o artístico, ou o ideológico, seja uma característica recorrente no discurso dos cientistas escritores na tentativa de legitimar a importância e o papel da ciência em busca das verdades sobre o mundo. A confirmação ou não desta hipótese merece investigação mais extensa e será objeto de estudo futuro.

\section{Considerações finais}

mundo configurado pelas TICs, pelo acesso crescente à internet, pelo fluxo livre de informações e pela convergência midiática proporciona novas possibilidades de aproximação e interação entre cientistas e sociedade. A coluna, antes impressa apenas em jornais sujeitos ao descarte no dia seguinte, agora está disponível na rede digital e "eternizada" em forma de livro, que pode ganhar sempre uma nova versão reeditada e reimpressa. 
Não se defende aqui a substituição da produção editorial periódica dos profissionais de imprensa sobre CT\&I, pela produção dos cientistas, nos meios impressos. $\mathrm{O}$ que se discute é a possibilidade de pesquisadores exercerem o importante papel de se comunicar diretamente com o público consumidor de mídias, de alternativas de aproximação dialógica entre cientistas, jornalistas e sociedade.

Os métodos tradicionais de divulgação científica na imprensa brasileira, baseado na reprodução monofônica e monossêmica de resultados científicos tidos como verdades absolutas, de maneira acrítica, simplista e imediatista, por meio de um texto objetivo, devem permanecer ainda por muitos anos. As condições de mercado impõem, muitas vezes, estes formatos. Mas o emprego de técnicas literárias para tratar de temas científicos, de descrição em detalhes dos ambientes e do cotidiano daqueles que compõem este universo, mesmo que ainda incipiente no Brasil, passa a ser mais fortemente discutido na academia e nos encontros entre divulgadores de ciência.

Comunicadores, escritores e cientistas tem algo em comum, são produtores culturais, produtores de sentido. A narrativa científica ganha em qualidade quando praticada em harmonia com a expressão artística, a liberdade poética, a manifestação criativa, o contexto histórico-cultural e a sutileza compreensiva. São novas formas de apreender e reportar a realidade complexa que nos cerca.

\section{Referências}

ALBAGLI, Sarita. Divulgação científica: informação científica para a cidadania? Ciência da Informação, Brasília, v. 25, n. 3, p.396-404, 1996.

BARBOSA, Marialva. Narrativa e cerimônia na televisão brasileira: ficcional e factual no acontecimento jornalístico. In: ADAMI, A. et. al. (Org.). Mídia, cultura e comunicação 2. São Paulo: Arte \& Ciência, 2003. p.217-223.

BARDIN, Laurence. Análise de conteúdo. 3.ed. Lisboa/Portugal: Edições 70, 2004.

BUENO, Wilson. Comunicação científica e divulgação científica: aproximações e rupturas conceituais. Informação \& Informação, Londrina, v. 15, n. esp, p. 1-12, 2010.

CASTELLS, Manuel. A sociedade em rede. São Paulo: Paz e Terra, 1999. 
GLEISER, Marcelo. Micro macro 2: reflexões sobre o homem, o tempo e o espaço. São Paulo: Publifolha, 2007.

GOMES, Isaltina Maria de Azevedo Mello. A ciência nos jornais. Galáxia, São Paulo, v. 2, n. 3, p. 93-108, 2002.

HERCULANO-HOUZEL, Suzana. O cérebro nosso de cada dia: descobertas da neurociência sobre a ida cotidiana. 2.ed, Rio de Janeiro: Vieira \& Lent, 2002.

KUHN, Thomas. S. A estrutura das revoluções científicas. São Paulo: Perspectiva, 1970.

MARQUES, Fabricio. A ciência compreendida: Uma safra de livros oferece a uma nova geração de leitores brasileiros temas científicos em linguagem atraente. Pesquisa Fapesp, São Paulo, n. 174, p.18-23, 2010. Disponível em: $<$ http://revistapesquisa.fapesp.br/2010/08/06/a-ci\%C3\%AAncia-compreendida/>. Postagem: ago. 2010.

MEDINA, Cremilda. O signo da relação: comunicação e pedagogia dos afetos. São Paulo: Paulus, 2006.

MELO, José Marques de. Jornalismo opinativo: gêneros opinativos no jornalismo brasileiro. 3.ed, Campos do Jordão : Mantiqueira, 2003.

REIMÃO, Sandra. Mercado editorial brasileiro 1960 - 1990. São Paulo: Com-Arte: Fapesp, 1996.

REINACH, Fernando. A longa marcha dos grilos canibais e outras crônicas sobre a vida na terra. São Paulo: Companhia das Letras, 2010.

REZENDE, Sérgio Machado. Produção científica e tecnológica no Brasil: conquistas recentes e desafios para a próxima década. Administração de Empresas, São Paulo, v.51, n.2 , p.202 -209, mar/abr 2011.

SILVA, Márcia Soares da. Mídia impressa e meio ambiente: uma análise da cobertura ambiental em três dos maiores jornais do Brasil. 2005. $170 \mathrm{f}$. Dissertação (Mestrado em Comunicação e Cultura) - Escola de Comunicação, UFRJ, Rio de Janeiro.

SCHMIDT, C. W. Communication Gap: The Disconnect Between What Scientists Say and What the Public Hears. Environmental Health Perspectives. Bethesda MD USA, v. 117, n. 12, p. A548-A551, dez 2009.

WOLF, Mauro. Teorias das comunicações de massa. 4.ed. São Paulo: WMF Martins Fontes, 2009. 